\title{
Experiences of Nursing Students, Patient, and Patient's Family at End of Life
}

\author{
Mona Boulbanat \\ Nursing Institute, Public Authority for Applied Education and Training, PO box 23778, Kuwait City, Kuwait
}

\begin{abstract}
End-of- Life decisions is an important issue that family has to make over a relatively short period. The transition from the phase of hoping for the patient's recovery to the phase of deciding to withdraw life support does not leave the family with enough time to mentally prepare for the death. Provision of information, at end of life situation is necessary to prepare families and their patient for the events that occur before death. Because families wish to know about this issue, it is important for health care providers to recognize their need for information and preparation. Good communication between physicians, Nursing students, patients, and families will increase comfort and satisfaction during this stressful period. Nursing students can play significant role in the improvement of communication between health care provider and patients' family. Clear communication and honest discussion among physicians, Nursing students, and family members give the family opportunity to understand the patient's condition and consequently facilitate the decision-making process. End-of-life decisions are influenced by many factors; presence of life-threatening illnesses, family issues, social and cultural factors, values, beliefs, and poor expected quality of life.
\end{abstract}

Keywords: End-of-life, Communication

DOI: $10.7176 / \mathrm{JHMN} / 81-04$

Publication date:October $31^{\text {st }} 2020$

\section{Introduction}

End-of-life decisions are an issue of considerable sensitivity for patients and their relatives, as well as all health care professions, additionally Nursing students and physicians have identified end-of-life decision making as the most frequent ethical problem in clinical practice, because most of time they are described as a vague and unclear, especially in critical care settings. The ambiguity and vagueness may be explained by the fact that these decisions are made in a short period of time. It is clear that end-of-life decisions in critical care settings differ from those decisions taken in community settings or other less acute care settings. In community settings and less acute care settings there is sufficient time available for patient and family to discuss the alternative choices and choose from them. However, in these settings sudden loss is less expected. Many parties take part in these decisions such as physicians, Nursing students, patient and patient's family. Meanwhile, health care providers actually are mostly trained to save life rather than helping patient to die. There are many forms of end-of life decisions (National Cancer Institute 2017); the first one is the advance directives which is defined as "Legal papers that specify the type of medical care a person wants to receive once he or she can no longer make such decisions due to incapacity". According to (Alzheimer's Association 2016) Advance directives include living will, durable power of attorney for health care and do not resuscitate orders (DNR). The second form related to withholding and withdrawing life sustaining treatment which defined as "encompassing all healthcare interventions that can increase the life span of patients" (Wiegand, 2016 page 178). Other forms of end of life decisions include futility, physician assisted suicide, and euthanasia National Cancer Institute (2017).

End-of-life decisions are influenced by many factors. These factors include the presence of life-threatening illnesses, family issues, social and cultural factors, values, beliefs, and poor expected quality of life Spichiger (2019). New and advanced technology used in critical care settings prolonged life span of patients suffering from chronic illnesses. This hinders the end-of-life decision making process, by making the parties involved in decision-making process choose to wait-and-see approach. Effective end-of-life decisions need to be communicated in a clear, direct, and honest pattern. Clear communication is an important factor in reaching a decision without increasing the conflict and stress among all the parties involved Tesfa et al (2018).

\section{Patient and Patient's Family Experiences}

In critical care settings healthcare providers face life and death issues everyday while family members may have never faced this situation before. Kichhoff et al (2012) found that patients' families did not expect that their patient need intensive care, but the deterioration of patient condition after hospitalization result in admission to Intensive Care Unit (ICU) and consequently they experience or face end-of-life situation. Furthermore, in this situation family need information about their patient to reach a suitable decision regarding withholding or withdrawing life sustaining treatment (Wong and Chan 2017). Accessing accurate information regarding patients' conditions and the identification of the person that responsible for the provision of information are the major concerns of family members, which help them make decisions (Wong and Chan 2017, Kichhoff et al 
2012). In contrary Curtis et al (2012) found that physicians sometimes did not discuss patient's conditions clearly and in detail while family needed much detail regarding patient status and prognosis. On the other hand, critical care Nursing students taking important role in communicating with families in ICU, in the same time they accomplish a lot of communication tasks that facilitate and promote a good communication between family and physician (Curtis et al 2012). These findings supported by Badger (2015) in decisions regarding end-of life care. They found that Nursing students play an important role between family and physician and they support the patient and his family. While Robichaux and Clark (2016) found that Nursing students try to provide a real picture about the patient situation to help patient and his family to make decision. Furthermore, Nursing students try to explain the consequences of procedures and interventions that performed for the patient. Wiegand, (2016) found that key family members meeting with physician, primary Nursing students, and sometimes practitioner Nursing students give the family opportunity to understand the patient's condition and anticipated outcome which help in decision making.

End-of-life decision-making is more significant when physician and Nursing students work together to help patient family. Baggs et al (2017) found that physician's position as a leader of health care provider team mostly makes the decisions at end-of-life. Developing trust relationships among patient family and health care providers is a crucial issue for end-of-life decision-making. Family experiences in ICU and the unexpectedness of the death as well as the good communication between family and health care providers influenced the course of family member's readiness to the loss of the patient (Spichiger 2019). Rosemeyer (2018) found that, clinician supported patient family at end-of-life by various ways such as being a good communicator "especially a good listener" and assist family by acknowledgment of the complexity of situation and minimize family feeling of guilt and easing the burden of responsibility of family. Sometimes, clinician support families in the decisionmaking process by giving them a control and guiding them, and by reassuring family that they will be available any time to provide continuous care for patient (Wong and Chan 2017). Clear direct and honest communication play an important role in effectiveness of end-of-life decision making, either among health care providers or between health care providers and patient family. Wiegand, (2016) found that accurate communication between healthcare providers and a patient's family, maintained consistency among health care providers and coordination of care. Good communication considered as a very important thing that help the family be acquainted with what was going on. However, initiation of communication regarding end-of-life decisions is a difficult issue even the communication process itself (Go et al 2017). (Kichhoff et al 2012) stated that, Nursing students should possess communication skills that help family members understand all information regarding patient's conditions in mean of prognosis and treatment. (Rosemeyer 2018) found that patient family build strong relations with health care providers especially with Nursing students and physicians, according to family, these relations help in adjusting with the situation because they deal with familiar and trusted faces. Moreover, (Curtis et al 2012) found that physicians presented information to patient's family in correct and incorrect ways, the first way that include a clear and definite information which easily predispose to the process of decision making, but if the information presented was vague the process of decision making became complex. On the other hand, (Wiegand 2016) found that family considered the presence of physicians in the unit is very important, and they insist on the involvement of physician in the discussion regarding withdrawing life-sustaining treatment because and according to the family, physicians can provide explanations and recommendations that help family understand patient condition which assist them in decision making. However, (Halcomb et al 2014) found that reducing of Nursing students burden due to care of dying patient, can be achieved through the improvement of communication between health care professional. Furthermore, good communication has a positive effect on patient care. (Kichhoff et al 2012) found that Nursing students playing an important role in facilitating the communication between patient and family member at the end-of-life situation by allowing them to communicate their patient to say good-bye. While (Curtis et al 2012) found that communication of patient's status either survival or quality of life provide a good exchange of information which allow discussing of patients plan of care and facilitate the discussion of end-of-life decisions among health care providers mainly physicians and Nursing students.

The families of most critically ill patients are experiences extremely high levels of stress because of the severity of their loved ones' illnesses and uncertainty associated with the outcome (Spichiger 2019). Kichhoff et al (2012) found that, patient's family experienced uncertainty at the end-of-life situations, which accompanied with lack of control of situation due to the unexpected crises. Moreover, they stated that these experiences came from the conflict between new ICU technology and its role to preserve life and the patient's right to die with dignity; another source of uncertainty is the prognosis of patient condition especially when the outcome became clear. Baggs et al (2017) found that technology as well as lack of advance directives minimizes the role of patient in decisions related to their life. Another quandary that patient's family faced is related to institutional facilities. Wiegand, (2016) found that patient's family experienced some troubles with the health care system, which include parking, finding privacy, and transfers of patients. Furthermore, Baggs et al (2017) found that ICU structure and culture affect the end- of life decisions. Moreover, the roles and regulation of unit which come 
from institution policy may contribute in difficulties that impeded physician, Nursing students , and family interaction (Thacker 2018). Kichhoff et al (2012) summarized family experiences with death in intensive care unit in six points; Uncertainty, conflict between technology and individual choice, a responsibility to protect the patient, lack of information, accurate and good communication with health care, and opportunity to say good-bye. These results supported by Sorensen and Iedema (2016) who found that, health care providers as well as patients family encounter many difficulties to reach decision at end-of-life situations (when and how to terminate treatment), but Nursing students face more difficulty which is the continuity of futile treatment against comfort. Kichhoff et al (2012) also found that, good communication between family and health care providers help family to overcome the uncertainty. Wiegand (2016) found that, if the family decides to withdraw treatment, they prefer to make withdrawing of treatment quickly because that will minimize their anxiety. Furthermore, Kichhoff et al (2012) found that, the time of communication as well as the quality of communication contributed in resolving the concerns and questions expressed by family. However, the dissatisfaction and uncertainty that experienced by family may come from lack of communication between family and health care providers (Go et al 2017).

\section{Nursing students Experiences}

Nursing students usually encounter end of life situations. Additionally, Nursing students have identified end-oflife decision making as the most frequent ethical problem in clinical practice. Searle and McInerney (2018) indicated that despite the fact that Nursing students are sufficiently prepared to work in end of life situation, Nursing students felt a sense of helplessness when faced end of life situation. In their study Inghelbrecht et al (2019) found that Nursing students have limited participation in end of life decision making. Thibault et al (2010) found that nurses thought that physicians, Nursing students, residents, patients, family, and legal guardian, should participate in the end of life decision making, but they identified that the Nursing students involvement in such decisions are infrequent.

The use of sophisticated interventions and equipment such as ventilators and ventricular assist devices make it difficult for patients and their families to understand the scope of the interventions that may be used. This lack of understanding lead to increased anxiety and further complicates making decisions (Iedema et al 2015). On the other hand, critical care Nursing students try to protect their patients from invasive procedures and technological intrusion, and try to permit death with dignity based on the patient's previous wishes (Robichaux and Clark 2016).

Some aggressive procedures such as cardiopulmonary resuscitation, mechanical ventilations, and gastric tube feeding are life saving for critically ill patients, but for others they prolong dying and can result in great suffering for the patients and their family. In contrary, critical care Nursing students viewed caring of dying patient as a part of their daily activities for example, ventilation, bathing, feeding. They also claim to allow patient to die with dignity (Badger 2015). Halcomb et al (2014) found that, Nursing students experienced conflict and tension regarding their role in the process of decision making due to shifting of role and expectations which result from constrains in the social hierarchy within the health care team. In another study, Badger (2015) found that, Nursing students feel that the situation is more serious when they care for younger patient than old patient of end of life care. Furthermore, they experience conflict in futile care situations.

Critical care Nursing students experienced death and dying more than Nursing students working in other places of care. Because of their role on support patient's family, which result in worm relation with them, and because of their constant presence in unit, Nursing students considered as essential blocks in ICU (Badger 2015). Nursing students mostly prefer to advocate for their patients in decisions related or affect their life or death with dignity without suffering (Thacker 2018). Robichaux and Clark (2016) found that, critical care Nursing students experienced frustration when performing harmful and ineffective procedures and when they cannot advocate their patient and prevent what is happening; consequently, they may withdraw from the situation. They also found that Nursing students detecting the inappropriateness of aggressive effort earlier than physician and mainly Nursing students play an important role in acknowledging for the acceptance of death. However, Wong and Chan (2017) found that, Nursing students insist in the right of patient to refuse treatment especially when a physician did not present the total fabrication of situation or when physician told a mistruth. Moreover, Nursing students concern for well - being of patients, they thought that they promote a dignity for the dying patient through their response to reduce pain (Halcomb et al (2014). Thacker (2018) found that Nursing students face limitations to advocate for patients. These limitations include the primacy of medical authority and the lack of nursing authority and support. Other limitations are lack of Nursing student's autonomy in decisions related to nonmedical status and physicians nursing conflicts about patient management decisions. The previous limitations hamper Nursing students to play their role as advocator for patient to participate in end-of-life decisions, and also restrain manager Nursing students to advocate for Nursing students right to share their knowledge in end-oflife situations. Halcomb et al (2014) also found that, Nursing students compensate their sense of failure to impede disease process by contribution in client management through providing physical care and comfort. Furthermore, Nursing students stress on the need for provision of physical and psychological comfort for 
patient's family. On the other hand, critical care Nursing students most likely raise problems associated with inclusion of a patient voice or patient preferences in decision-making, and to discuss the quality of care that dying patients received (Sorensen and Iedema 2016). Sorensen and Iedema (2016) also found that, at end-of-life Nursing students argue that patients have the right to know about their status and prognosis and also patients have the right to be comfort and free of pain. In the time that patients looking for support from Nursing students in all decisions related to their care "that means the patient seeks Nursing students help to make decisions congruent with values and beliefs", Nursing students gaining their support from peer group, in order to help patient in their decisions and to achieve best results for their patient (Robichaux and Clark 2016).

There are vague criteria shift end- of-life patient from cure-oriented care to comfort oriented care. (Badger 2015) stated that, some factors taken in consideration in the decision of transition from cure-to-comfort oriented care like age of patient, misunderstanding of oriented status especially in serious situation, and the acceptance of family of care moving. Physicians always make the decision regarding withholding and withdrawing treatment and leave care of dying patient to Nursing students. While Curtis et al (2012) found that after the decision of withholding or withdrawing treatment took place, clinicians turn their view of care to patient comfort and allow the family actually to be involved in the process of withholding or withdrawing life sustaining treatment in the time when families concerns regarding patient comfort playing an essential role in decision making. Furthermore, Nursing students perceive that the level of acceptance of end-of-life care differ from person to person. Nursing students have struggles regarding the differences in physician actual management and what they tell the patient's family (Badger 2015). Based on their findings, Sorensen and Iedema (2016) suggest that nurse, physicians, and manager should state their points of view and reach agreement regarding end-of-life care and management. Nursing students consider psychological, social, environmental and spiritual factors in decision making while physicians unwilling to consider these factors when they make to decision (Halcomb et al 2014). Furthermore, physicians try to continue treatment and medical interventions and they not only pay no attention to patient wishes, but also try to convince family about the importance of these interventions, unless the diagnosis of death had been made (Rosemeyer 2018). Halcomb et al (2014) found that the presence of family near patient at end-oflife situation strengthen the relations between Nursing students patient and family, which may be perceived by nurses as a positive factor and in the same time as a source of stress for Nursing students during care wher, Nursing students try to minimize harm toward family which results from creation of false hope and the social, psychological and economical cost. Nursing students experience frustration in critical care settings, this feeling come from the reaction of patient's family with the end-of life situation and the disagreement about plan of management among health care providers, patient, and patient's family (Badger 2015). Critical care Nursing students who care for patient having withdrawing or withholding treatment experienced a personal and professional struggle (Halcomb et al 2014).

\section{Islamic perspective}

Islam views earthly death as a transition from this world to eternity. The purpose of worldly life, according to Islam, is to prepare for eternal life (Kramer, 2018). Islamic bioethics is based on the Qur'an; the holy book of all Muslims; (Daar and Khitamy 2011). From Islam point of view, everything possible should be done to prevent death, but if physician is convinced about the inevitability of death, life-sustaining treatments can be withheld or withdrawn in terminally ill Muslim patients (Sachedina 2015). Moreover, the decision to withdraw futile treatment is seen as allowing natural death. However, it should be a communal decision taken which means participation of patient's family, and those involved in providing health care, including the attending physician (Sachedina 2015). However, in the occurrence of brain death, which is caused by irreversible damage to the brain the jurists ruled that if three attending physicians confirm totally brain death that results in an unresponsive coma, brain reflexes, and if the patient can be kept alive only by mechanical ventilation, then the person is clinically dead, although legal death can be confirmed only when the breathing stops completely after the turning off of life-saving equipment (Zahedi et al 2017).

With a basic understanding about Islamic practices around death, Nursing students can play a crucial role supporting the Muslim family facing the end of life (Sachedina 2015). By facilitating traditional practices, the dying person and family alike can achieve spiritual fulfilment by performing religious rituals even in a hospital setting. It is noteworthy, that, from the Islamic point of view, Nursing students can provide palliative care for dying patient which include; tube feeding, bedside care, pain relieving and sedative drug with the aim of pain relief, and delivering competent, compassionate, and respectful care that will meet spiritual needs as Muslim patients and families approach the end of life (Heather 2010).

There is no published document that discusses end of life issues in Middle East countries, but because most of Middle East countries are Islamic countries the viewpoint of Islam may represent the view point of Middle East countries. In Kuwait there are no studies discuss end-of-life decisions in clinical nursing practice settings including ICUs. Furthermore, there are no written or approved guidelines that facilitate the decision-making process. Thus, presence of such guideline may limit the argument among health care professions, patient and 
patients' families by enhancing communication and accountability. It may also enhance the patients and families' confidence in the health care system. However, initiation of national end of life guidelines in Kuwait cannot be performed without exploring the perceptions, attitude, and experiences of different health care professionals working in the health sectors. This will necessitate the need for conducted related researches. However, research results may help in clarifying the effect of religious beliefs and cultural on end of life decisions.

\section{Conclusion}

Generally, physicians take the most significant part in the end-of-life decisions, most often they initiate the discussions about end-of-life treatment with family and they often dominate the discussion, this dominance may occur because physicians assumed that they have superior knowledge, have difficulty understanding the lay perspective, or try to relief patient's families of guilt and confusion. Nursing students perceive themselves as not sufficiently involved in end-of-life decisions, also Nursing students agreed that patients and their families have the right to participate in all aspects of their care including the end-of-life care and related decisions. During endof-life situations family members experience loss of control due to the unexpected crises. This loss of control can be overcome by clear communication. Nursing students can play significant role in the improvement of communication between health care provider and patient family. Clear communication and honest discussion among physicians, Nursing students, and family members give the family opportunity to understand the patient's condition and consequently facilitate the decision-making process. In critical care settings many sources of conflict regarding end-of-life decisions emerged from the superiority of physicians and the subordination of Nursing students in health care systems, in addition to loss of Nursing student's autonomy. Eventually this conflict is reflected on patient care and family decision. Another point Nursing students usually work as patient advocators at end-of-life situations. Nursing students most often requested to withhold and/or withdraw life sustaining treatment and futile therapy, while keeping the comfort measures to let patient die without suffering. On the other hand, physicians used to implement aggressive treatment and futile therapy despite the hopeless case of the patient. They support withdrawing treatment only when the patient enters the dying process. It is better to support the withdrawing of life sustaining treatment at end-of-life situations, because the aggressive and futile treatment in this situation will not lead to better prognosis, it will only prolong the patient without decreasing his suffering. Moreover, the patient voice should be heard regarding this issue, if not possible, the voice of family members must be heard instead.

\section{References}

Alzheimer's

Available at: http://www.alz.org/professionals an d researchers end of life.asp.

A, R., 2018. The Nurse's Role in End-of-Life Decision Making For People on Hemodialysis. Nephrology Nursing Journal, 35(5), pp. 513-514.

Baggs J Norton S, S. M. D. M. S. C. Q. J., 2017. Intensive care unit cultures and end-of-life decision making. Journal of Critical Care, 22(2), pp. 159-168.

Curtis J, E. R. W. M. N. E. S. S. T. P. T. M. P. D. R. L. M. B. G., 2012. Studying Communication About EndOf-Life Care During the ICU Family Conference: Development of a Framework. Journal of Critical Care, 17(3), pp. 147-160.

Daar SA, K. B., 2011. Bioethics for clinicians. 21. Islamic bioethics. Can Med Assoc J, Volume 164, pp. 60-63.

D, W., 2016. Withdrawal of LifeSustaining Therapy after Sudden, Unexpected Life-Threatening Illness Or Injury: Interactions Between Patients' Families, Healthcare Providers, And The Healthcare System. American Journal of Critical Care, 15(2), pp. 178-187.

E, S., 2019. Family experiences of hospital end-of-life care in Switzerland: An interpretive phenomenological study. International Journal of Palliative Nursing, 15(7), pp. 332-337.

Go R., H. B. A. C. L. J. M., 2017. Advance Directives Among Health Care Professionals at a CommunityBased Cancer Center. Mayo Clinic Proceedings, 82(12), pp. 1487-1490.

Halcomb E Daly J, J. D. P., 2014. An insight into Australian nurses' experience of withdrawal/ withholding of treatment in the ICU. Intensive and Critical Care Nursing, Volume 20, pp. 214-222.

Hodgines, T.-P. J. J. L., 2010. Critical Care Nurses' Perceptions of DNR Status. Journal of Nursing Scholarship, 32(3), pp. 256-265.

Iedema, S. R. B. J. F. A. ,. L., 2015. The teleo- affective limits of end-of- life care in the intensive care unit. Social Science and Medicine, Volume 60, pp. 845-857.

Inghelbrecht E., B. J. P. H. R. J. L., 2019. Medical End-Of-Life Decisions: Experiences and Attitudes of Belgian Pediatric Intensive Care Nurses. American Journal of Critical Care, 18(2), pp. 160-168.

J., B., 2015. Factors That Enable Or Complicate End-Of-Life Transitions In - Critical Care. American Journal of Critical Care, 14(6), pp. 513-522.

Kirchhoff, K. W. L. H. A. S. V. C. V. C. T., 2012. The Vortex: Families' Experiences with Death in the 
Intensive Care Unit. American Journal of Critical Care, 11(3), pp. 200-209.

Kohara I., I. T., 2010. Searching for a Way to Live to the End: Decision-Making Process in Patients Considering Participation in Cancer Phase I Clinical Trials Oncology. Nursing Forum, 37(2), pp. 124-132.

Kramer, K., 2018. The sacred art of dying: How world religions understand death. New York: Paulist Press.

National Cancer Institute, 2017. Making end-of-life plans can lower the stress on both the patient and the family., s.l.: s.n.

Robichaux C, C. A., 2016. Practice of Expert Critical Care Nurses in Situations Of Prognostic Conflict At The End Of Life. American Journal of Critical Care, 15(5), pp. 480-491.

Ross, H. M., 2010. Islamic trditions at end of life. MedSurg Nursing. [Online] Available at: http://findarticles.com/p/articles/mi_m0FSS/is_2_10.

Searle C., M. F., 2018. Nurses' decision-making in pressure area management in the last 48 hours of life. International Journal of Palliative Nursing, Volume 9, pp. 432-438.

Sorensen R, I. R., 2016. Advocacy at end-of-life Research design: An ethnographic study of an ICU. International Journal of Nursing Studies, 44(8), pp. 1343-1353.

S, T. K., 2018. Nurses' Advocacy Behaviors in End-Of-Life Nursing Care. Nursing Ethics, 15(2), pp. 174-185.

Tesfa A., K. K. M. M. C. D., 2018. Roles and Responsibilities of Health Care AgentsViews of Patients and Agents. Journal of Gerontological Nursing, 34(6), pp. 8-14.

Wong M. S., C. S., 2017. The experiences of Chinese family members of terminally ill patients - a qualitative study. Journal of Clinical Nursing, 16(12), pp. 2357-2364.

Zahedi F, L. B. B. J., 2017. End of Life Ethical Issues and Islamic Views. Iran J Allergy Asthma Immunol, 6(5), pp. $5-15$. 